\title{
Modulation of Nucleotide Triphosphate Diphosphohydrolase-1 (NTPDase-1)/cd39 in Xenograft Rejection
}

\author{
Masato Imai, ${ }^{1,3}$ Ko Takigami, ${ }^{1}$ Olaf Guckelberger, \\ Keiichi Enjyoji, ${ }^{4,5}$ R. Neal Smith, ${ }^{6}$ Yuan Lin, ${ }^{1}$ Eva Csizmadia, ${ }^{2}$ \\ Jean Sévigny, ${ }^{2}$ Robert D. Rosenberg, ${ }^{4}$ Fritz H. Bach, ${ }^{1}$ and \\ Simon C. Robson ${ }^{1,2}$
}

Departments of ${ }^{1}$ Surgery and ${ }^{2}$ Medicine, Beth Israel Deaconess Medical Center, Harvard Medical School, Boston, Massachusetts, U.S.A.

${ }^{3}$ Second Department of Surgery, Asahikawa Medical College, Asahikawa, Hokkaido, Japan

${ }^{4}$ Department of Biology, Massachusetts Institute of Technology, Cambridge, Massachusetts, U.S.A.

${ }^{5}$ Laboratory of Clinical Pathology, National Cardiovascular Center, Suita, Osaka, Japan

${ }^{6}$ Immunopathology Unit, Department of Pathology, Massachusetts

General Hospital, Boston, Massachusetts, U.S.A.

Accepted October 1, 1999.

\begin{abstract}
Background: There is increasing evidence showing that extracellular nucleotides may be important mediators of vascular inflammation. Nucleotide triphosphate diphosphohydrolase-1 (NTPDase-1, identical to CD39), the major vascular endothelial ectonucleotidase, is responsible for the hydrolysis of both extracellular ATP and ADP in the blood plasma to AMP. Studies were therefore conducted to evaluate the role of vascular NTPDase-1/cd39 in modulating platelet activation and vascular injury in cardiac xenografts.

Materials and Methods: Cardiac xenografts from both wild-type and $c d 39$ knockout mice (C57BL/6 $\times$ $129 \mathrm{Svj}$ ) were transplanted into Lewis rats. Alterations in cd39 mRNA transcripts and NTPDase activity expression were evaluated in wild-type grafts in untreated rats and then following complement depletion and immunosuppression. Rejection responses were studied with both mutant and wildtype grafts in the following models: presensitization with or without complement depletion, comple-
\end{abstract}

ment depletion alone, and with chronic immunosuppression to induce long-term graft survival.

Results: NTPDase biochemical activity in wild-type xenografts rapidly decreased after transplantation but soon rebounded with graft survival. Elevated levels of cd39 mRNA with associated increases in NTPDase activity were observed in all long-term surviving wild-type grafts. Hyperacute xenograft rejection times were comparable in wild-type and mutant grafts but cd39-deficient grafts were subject to more rapid rejection and exhibited pronounced vascular injury in complement-depleted, presensitized rats. The $c d 39$-deficient grafts in immunosuppressed recipients were subject to increased intravascular platelet sequestration and fibrin deposition; this resulted in focal myocardial infarction in long-term surviving mutant xenografts.

Conclusions: Augmentation of NTPDase-1 activity may be an important adaptive response for graft survival. Our results suggest that NTPDase-1/cd39 influences pathways of vascular injury in cardiac xenografts. 


\section{Introduction}

Vascular injury and platelet activation with consequent sequestration are significant pathological features in all forms of xenograft rejection (1-4). This process is further potentiated by molecular barriers between species and the loss of protective thromboregulatory elements from the vasculature (3). This modality of xenograft injury is important, as specifically targeting platelet aggregation and blocking thrombin activity prolong graft survival (5-7).

A major thromboregulatory element associated with the vascular endothelium is the ectonucleotidase termed nucleoside triphosphate diphosphohydrolase-1 (NTPDase-1; ATPDase or EC 3.6.1.5). This ectoenzyme has the capacity to metabolize ATP and ADP to AMP (8-11). AMP is further converted to adenosine by $5^{\prime}$ nucleotidase (12). We and others have demonstrated that CD39, originally characterized as an activation marker on B cells (13), has identity to the vascular ATPDase or NTPDase-1 $(8,14-16)$.

NTPDase- 1 plays a critical role in the regulation of platelet thrombosis and blood fluidity $(8,15,16)$, at least in part by modulating purinergic receptors expressed on leukocytes, platelets, and endothelium $(17,18)$. Nucleotides are released from activated endothelial cells (EC) and are also secreted in high concentrations by platelets following their stimulation with exogenous ADP, collagen, thrombin, or activated complement components $(10,19)$. Purinergic mediators may be responsible for recruitment with sequestration of activated platelets in the microvasculature and could also play a role in EC activation responses (1). For instance, ADP is a potent agonist of platelet aggregation following activation of type 2 purinergic (P2) receptors $(18,19)$. ATP also induces pore formation in cell membrane following P2X7 receptor stimulation $(20,21)$. Both ATP and ADP stimulate various cell types, generally in a proinflammatory manner (22-25). Therefore, decreases in extracellular ATP and ADP mediated by CD39 tend to abrogate aggregatory and proinflammatory stimuli $(8,9,23)$. Furthermore, adenosine functions as an antithrombotic and anti-inflammatory stimulus $(18,26)$, providing a second mechanism by which NTPDase-1 down-regulates platelet aggre-

Address correspondence and reprint requests to: Dr. Simon C. Robson, Beth Israel Deaconess Medical Center, Harvard Medical School, 99 Brookline Avenue, Boston, MA 02215, U.S.A. Phone: 617-632-0881; Fax: 617-632-0880; E-mail: srobson@caregroup.harvard.edu gation and inflammation, by providing AMP for $5^{\prime}$-nucleotidase action $(1,12,26)$.

Hyperacute rejection (HAR) is caused by the reaction of recipient xenoreactive natural antibodies and complement with the EC lining the discordant xenograft vasculature $(1,4,27,28)$. If HAR is abrogated, another phase of rejection leads to graft loss around days 3-4 by a process referred to as delayed xenograft rejection (DXR) $(3,27,28)$. Accommodation refers to the survival of a graft in the presence of anti-graft antibodies and complement (4). This can be studied by inducing complement depletion and administering cyclosporin A (CsA) in concordant small animal combinations $(3,4)$.

We have already established that vascular ATPDase/CD39 expression may be rapidly decreased by reperfusion injury (29), oxidant stress $(8,30)$, or cytokine-mediated EC activation responses as seen in xenograft rejection $(31,32)$. However, the kinetics and functional role of NTPDase-1/CD39 in modulating xenograft survival requires further evaluation. To verify the importance of NTPDase-1/cd39 in this setting, we have evaluated NTPDase activity during the rejection and accommodation of cardiac wild-type mouse xenografts and have contrasted survival of $c d 39$ knockout mouse (18) grafts with those of matched wild-type organs.

\section{Materials and Methods}

Animals

Mutant mice deficient in $c d 39$ were generated, validated, and characterized as described previously (18). Murine hearts from matched wildtype $(\mathrm{C} 57 \mathrm{BL} / 6 \times 129 \mathrm{Svj}$ strain; Taconic, Germantown, NY) or chimeric $c d 39$ knockout mice were used as donor organs for transplantation into inbred adult male Lewis rats (Harlan Sprague Dawley, Indianapolis, IN), using standard techniques.

All animals were housed in accordance with guidelines from the American Association for Laboratory Animal Care, and research protocols were approved by the International Animal Care and Use Committees of the Beth Israel Deaconess Medical Center.

\section{Surgical Model}

Animals were anesthetized by a combination of methoxyflurane (Pitman-Moore, Mundelain, IL) inhalation, and pentobarbital (Abbott, North 
Chicago, IL) at a dose of $40-60 \mathrm{mg} / \mathrm{kg}$ (intraperitoneal) during all procedures. Heterotopic cardiac transplants into the abdomen were performed as described previously $(33,34)$. Graft survival was assessed every $8-12$ hr by palpation. Rejection was diagnosed by cessation of ventricular contractions and confirmed by direct visualization and by histologic examination.

\section{Sensitization and Reagent Administration}

In selected cases, recipients were sensitized 7 days prior to transplantation by intraperitoneal injection of $30 \times 10^{6}$ wild-type murine splenocytes. To achieve complement depletion, cobra venom factor (CVF; Quidel, San Diego, CA) was injected intraperitoneally $l$ day before transplantation (at a dose of $60 \mathrm{U} / \mathrm{kg}$ ) and on the day of operation post-anesthesia (at $20 \mathrm{U} / \mathrm{kg}$ ). Immunosuppression involved the administration of cyclosporine A (CsA; Novartis Pharma, Basel, Switzerland) daily intramuscularly (at a dose of 15 $\mathrm{mg} / \mathrm{kg}$ ) to the termination of experiment $(33,34)$.

\section{RNA Extraction and Semiqualitative RT-PCR Determinations}

Total RNA was extracted using the TRIzol LS Reagent (GIBCO BRL Products, Gaithersburg, $\mathrm{MD}$ ) from mouse cardiac xenografts harvested at $1,3,6,12,24,48,72 \mathrm{~h}$, and 60 days after transplantation (or removed following rejection). Primers used in the reverse transcriptasepolymerase chain reaction (RT-PCR) assays were as follows: mouse CD39 (sense primer, 5'CGAGAAGGTTGTGAATGTAAGTGAG-3'; antisense primer, 5'-GAGAAGCAGTACTCACTCAGGTACTTCTCC-3'), $\beta$-actin (sense primer, 5'CCTGACCGAGCGTGGCTACAGC-3'; antisense primer, 5' -AGCCTCAGGGCATCGGAAC-3').

Reverse transcription was performed with First Strand cDNA Synthesis kit for RT-PCR (Boehringer Mannheim, Indianapolis, IN). PCR was performed using AmpliTaq DNA Polymerase (Perkin-Elmer, Foster City, CA), and PCR conditions were as follows: $\mathrm{CD} 39$, initial denaturation at $94^{\circ} \mathrm{C}$ for $30 \mathrm{sec}$ and 24 cycles of $94^{\circ} \mathrm{C}$ for 30 sec, $60^{\circ} \mathrm{C}$ for $30 \mathrm{sec}, 72^{\circ} \mathrm{C}$ for $2 \mathrm{~min} 30 \mathrm{sec}$, with a final extension of $10 \mathrm{~min}$ at $72^{\circ} \mathrm{C} ; \beta$-actin initial denaturation at $95^{\circ} \mathrm{C}$ for $4 \mathrm{~min}$ and 24 cycles of $95^{\circ} \mathrm{C}$ for $1 \mathrm{~min}, 55^{\circ} \mathrm{C}$ for $1 \mathrm{~min}, 72^{\circ} \mathrm{C}$ for $1 \mathrm{~min}$, with a final extension of $5 \mathrm{~min}$ at $72^{\circ} \mathrm{C}$. The amplified products were resolved on $1.5 \%$ ethidium bromide-stained agarose gels. The band sizes were estimated by ultraviolet (UV) visualization and using Bio-Rad Multi-Analyst/PC Version 1.1 (Bio-Rad Laboratories, Hercules, CA). The intensity of the $\beta$-actin PCR product was used as an internal control.

\section{NTPDase Activity Assays}

Xenografts were harvested and tissue homogenates or particulate fractions prepared at $1,3,6$, $12,24,48$, and $72 \mathrm{~h}$ and 45,60 , and 75 days after transplantation or after rejection as described previously $(34,35)$. Protein concentrations were measured by the technique of Bradford (36) and NTPDase enzymatic activity was determined as before $(35,37)$.

\section{Western Analysis}

Expression of $\mathrm{CD} 39$ protein level was determined, followed by Western blotting. Protein samples (17 $\mu \mathrm{g}$ per lane) were fractionated on a $10 \%$ SDS-polyacrylamide gel under nonreducing conditions, transferred to polyvinylidene difluoride membrane (Immobilon P; Millipore, Bedford, MA) by semidry electroblotting, and then probed with anti-mouse ATPDase polyclonal antibody (18). Bound primary antibody was detected by chemiluminescence reagent (NEN Life Science Products, Boston, MA).

\section{Histology and Immunohistology}

The xenografts were snap frozen and stored at $-80^{\circ} \mathrm{C}$ or fixed in neutral-buffered formaline for hematoxylin and eosin staining. Hematoxylin and eosin stains were done in paraffin sections; immunostainings were performed on cryostat sections, counterstained with hematoxylin. Expression of CD39 was visualized using rabbit polyclonal antibody generated specifically against mouse ATPDase (18). Detection of P-selectin as a surrogate marker for platelet sequestration was carried out using rabbit anti-mouse/rat P-selectin polyclonal antibodies (Pharmingen, San Diego, CA).

\section{Statistical Analysis}

All values are expressed as mean \pm SEM. Statistical analysis was performed with the Student's $t$-test and significance was defined as $p<0.05$. 


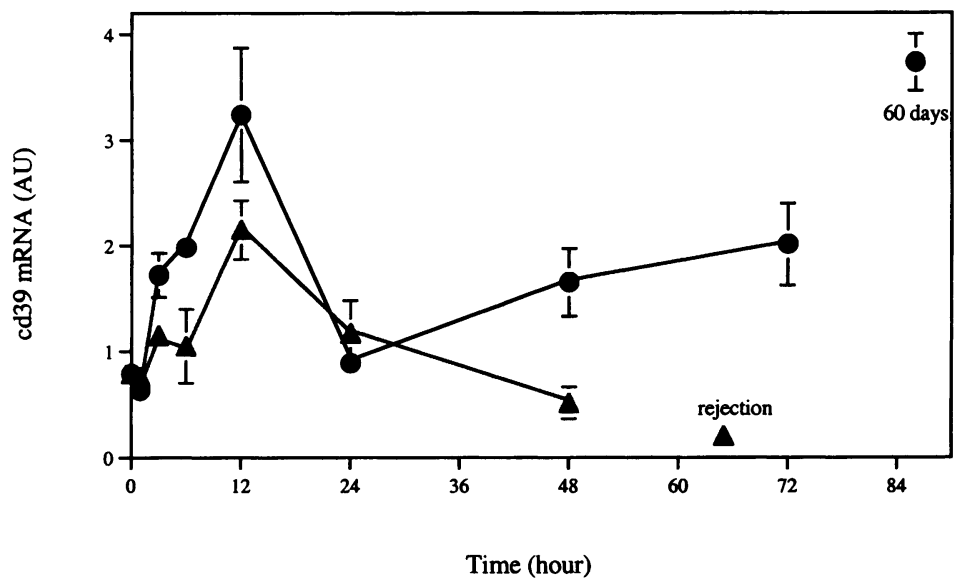

Fig. 1. cd39 mRNA levels in wild-type cardiac xenografts post-transplantation. In the long-term survival model (circles), recipients were treated with CVF and CsA. In the concordant rejection model (triangles) recipients received no immunosuppressive agents either before and after transplantation. Rejection times varied from 58 to $65 \mathrm{hr}$. RNA extraction and RT-PCR analysis were performed as described in Materials and Methods. Absorbance units (AU) were calculated by ratio of $\beta$-actin: cd39 RT-PCR products. Results are the mean \pm SEM for three mice per time point.

\section{Results}

\section{Wild-type Xenograft Rejection}

Concordant mouse cardiac xenografts were rejected after 2 days in untreated rat recipients. In these xenografts, early determinations of cd39 transcript levels after transplantation were comparable to baseline [0.79 \pm 0.12 at time zero and $0.76 \pm 0.05$ absorbance units (AU) at $1 \mathrm{hr}$; mean \pm SEM $n=3$ ] but then doubled (to $2.15 \pm$ $0.28 \mathrm{AU}$ ) at $12 \mathrm{hr}$ post-transplantation. Levels appeared to then steadily decrease to the time of rejection (Fig. 1).

Total NTPDase activities decreased soon after transplantation (ATPase; $156.7 \pm 27$ to $94 \pm 24$ $\mathrm{nmol} / \mathrm{mg}$ protein $/ \mathrm{min}$ at $6 \mathrm{hr}$. ADPase; $36.3 \pm$ 2.8 to $16 \pm 1.5 \mathrm{nmol} / \mathrm{mg}$ protein $/ \mathrm{min}$ at $1 \mathrm{hr}$, mean $\pm \operatorname{SEM} n=3$ ) (Fig. 2A). However, comparable levels of immunoreactive cd39 were observed on Western blotting (Fig. 3A) and by immunostaining performed on histological sections at all time points sampled to rejection (Fig. 4B).

Cardiac rejection was associated with vascular thrombosis, edema, myocardial necrosis, and host leukocyte infiltration (Fig. 4A). P-selectin staining revealed platelet sequestration with evidence for microvascular thrombosis in rejected grafts (Fig. 4C).

\section{Accommodated Wild-type Xenografts}

As before, levels of cd39 post-transcripts were initially comparable in grafts transplanted into complement-depleted and immunosuppressed rats $(0.79 \pm 0.06$ at baseline and $0.63 \pm 0.33 \mathrm{AU}$ at $1 \mathrm{hr}$ ) but then also substantially increased at the 12-hr post-transplantation time point. In contrast to the rejecting grafts, levels then grad- ually increased to much higher levels associated with prolonged graft survival $(3.73 \pm 0.27 \mathrm{AU}$ at 60 days) (Fig. 1).

As in the previous experiments, NTPDase activities initially decreased (ATPase; $156.7 \pm 27$ to $72.7 \pm 20 \mathrm{nmol} / \mathrm{mg}$ protein $/ \mathrm{min}$, ADPase; $36.3 \pm 2.8$ to $14.3 \pm 2.3 \mathrm{nmol} / \mathrm{mg}$ protein $/ \mathrm{min}$ ) at $12 \mathrm{hr}$ after transplantation. However, NTPDase functional activity then recovered at around 48 $\mathrm{hr}$ (ATPase; $186.7 \pm 17 \mathrm{nmol} / \mathrm{mg}$ protein $/ \mathrm{min}$, ADPase; $40 \pm 4.7 \mathrm{nmol} / \mathrm{mg}$ protein $/ \mathrm{min}$ ) (Fig. 2B) and then approximately doubled by 72 hr (ATPase; $366.4 \pm 9.8 \mathrm{nmol} / \mathrm{mg}$ protein $/ \mathrm{min}$, ADPase; $101 \pm 0.5 \mathrm{nmol} / \mathrm{mg}$ protein $/ \mathrm{min}$ ) compared with hearts assayed at baseline. NTPDase levels remained elevated to 60 days (Fig. 5). Analysis by Western blot showed that cd39 levels increased parallel to NTPDase activity within this incremental phase (Fig. 3B) and again during the period of prolonged survival (Fig. 6A).

\section{NTPDase Levels in Mutant Grafts}

Interestingly, mutant mice cardiac grafts had baseline NTPDase activities (ATPase; $142.1 \pm 9.8$ $\mathrm{nmol} / \mathrm{mg}$ protein $/ \mathrm{min}$, ADPase; $36.2 \pm 4.6$ $\mathrm{nmol} / \mathrm{mg}$ protein $/ \mathrm{min}$ ) comparable to those of wild-type organs; this activity could be ascribed to other $c d 39$ family members expressed by the heart. These biochemical activities did not substantially change during the phase of graft survival to 60 days; however, a late increase in both ATPase and ADPase activities was observed between 60 and 75 days (Fig. 5). As anticipated, Western blotting confirmed that mouse cd39 antigen was not expressed by mutant cardiac grafts at any time point tested (Fig. 6B). 

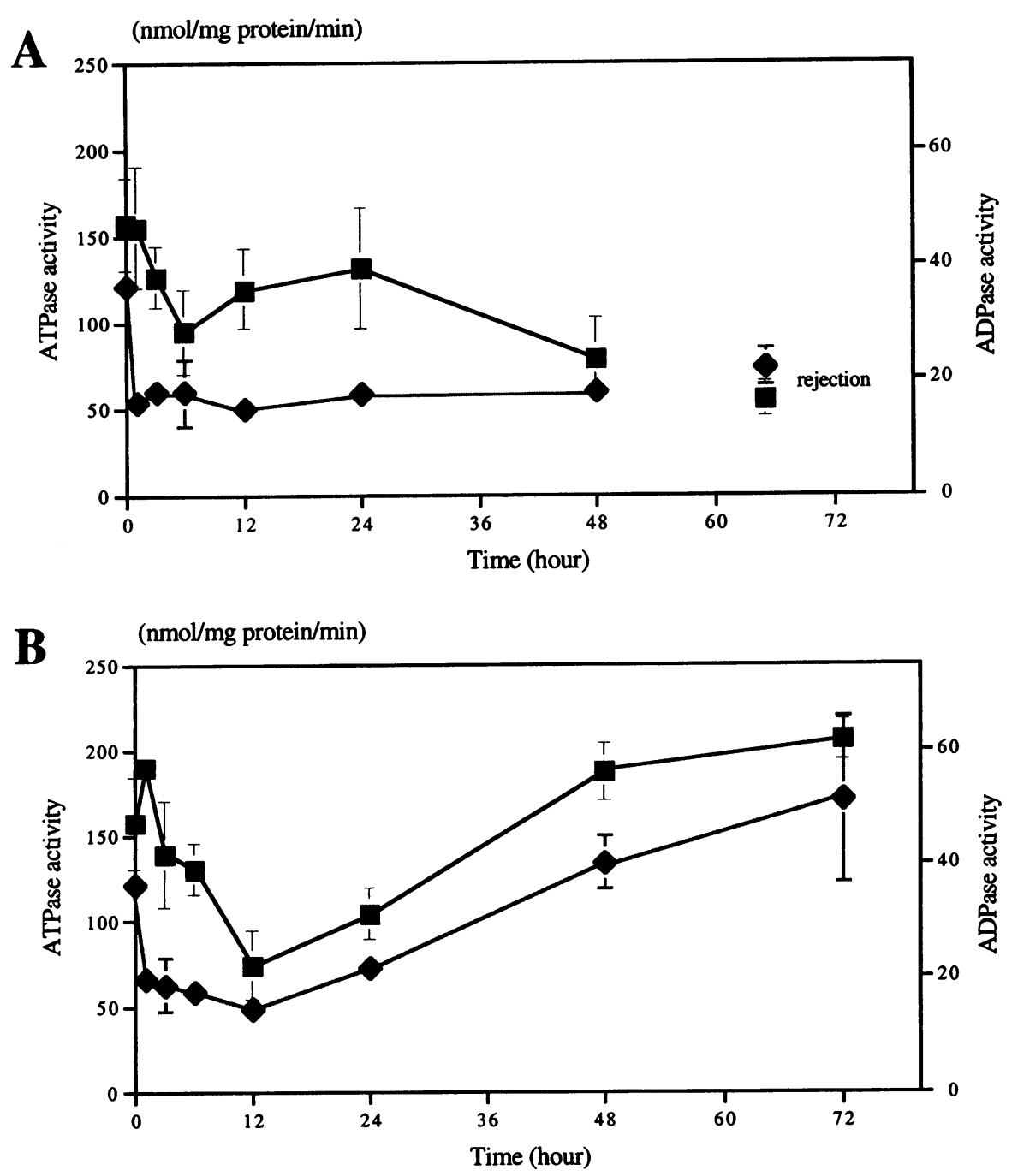

Fig. 2. NTPDase activities in wild-type cardiac xenografts (0-72 hr). (A) Concordant rejection model. ATPase activity (squares) and ADPase activity (diamonds) were measured using graft homogenates.
Results are the mean \pm SEM for three mice per point. Rejection times varied (58-65 hr). (B) Accommodation and long-term survival model. Squares show ATPase and diamonds show ADPase.
Survival of Wild-type (cd39 $\left.{ }^{+/+}\right)$and Knockout (cd39-1-) Murine Cardiac Xenografts

Both wild-type and knockout grafts in untreated control animals (without presensitization, CVF, and CsA) survived only 2 days post-transplantation. CVF administration prolonged graft survival equally in both groups to 4 days. Wild-type and mutant grafts were also rapidly lost in sensitized recipients by HAR (within $1 \mathrm{hr}$ ). In the rejection model associated with complement depletion in presensitized recipients, mutant graft survival times were significantly shorter than for wildtype organs $(21 \pm 9$ versus $43 \pm 7 \mathrm{hr} ; n=6, p<$ $0.001)$.

All wild-type mice grafts survived over 45 days following administration of CVF and CsA and were considered to have become accommodated $(33,34)$. Mutant cardiac grafts also survived long term in the presence of antibody and reconstituted complement (Table 1) with no apparent decreases in overall graft survival, up to 75 days after transplantation.

Immunopathology of Wild-type and Knockout Grafts during Accommodation

Hematoxylin and eosin-stained sections of wildtype grafts revealed excellent preservation of myocardial architecture, normal vasculature, and no evidence of thrombosis at 60 days post- 
A

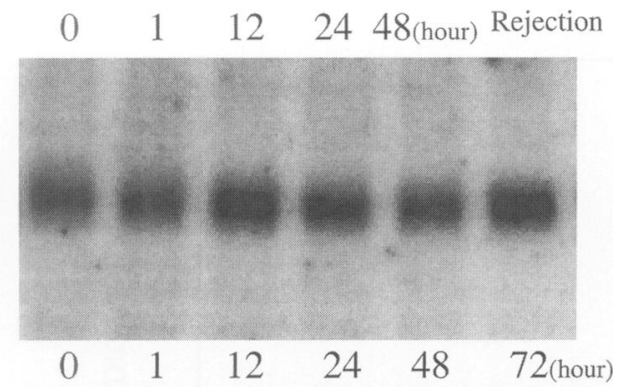

B

$\operatorname{cd} 39(78 \mathrm{kDa})$

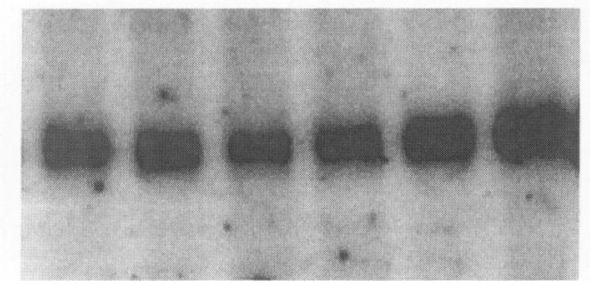

Fig. 3. Western analysis of cd39 expression in wild-type cardiac xenografts $(0-72 \mathrm{hr})$. Protein extracts from cardiac grafts were fractionated by SDS-PAGE and analyzed by protein immunoblot analysis with an anti-mouse ATPDase antibody. Native cd39 is expressed as a $78 \mathrm{kDa}$ band. (A) Concordant rejection model; (B) accommodation model.

transplantation (Fig. 7A). Moreover, cd39 was highly overexpressed in the wild-type graft endothelium at 60 days (Fig. 7B) and endocardium (data not shown); comparable cd39 staining patterns were also observed at 45 and 75 days post-transplantation (data not shown). P-selectin expression in association with rat platelet deposition was not detectable within the vasculature or tissues of wild-type grafts at 60 days (Fig. 7C) and 75 days post-transplantation (data not shown).

Hematoxylin and eosin-stained sections of mutant grafts showed minimal cellular infiltration in grafts at 60 to 75 days post-transplantation (Fig. 8A). Moderate-sized healing infarctions in the ventricular walls were observed at 75 days after transplantation (Fig. 9). There was no detection of cd39 in knockout grafts; infiltrating rat cells did not stain with the anti-mouse cd39 antibodies used (Fig. 8B). P-selectin expression was observed mainly in the intravascular space, in association with platelet sequestration (Fig. $8 \mathrm{C}$ ) at 45,60 , and 75 days post-transplantation; some graft endothelial expression was also noted, but at relatively low levels.

\section{Discussion}

We have demonstrated that graft NTPDase biochemical activities decrease immediately after

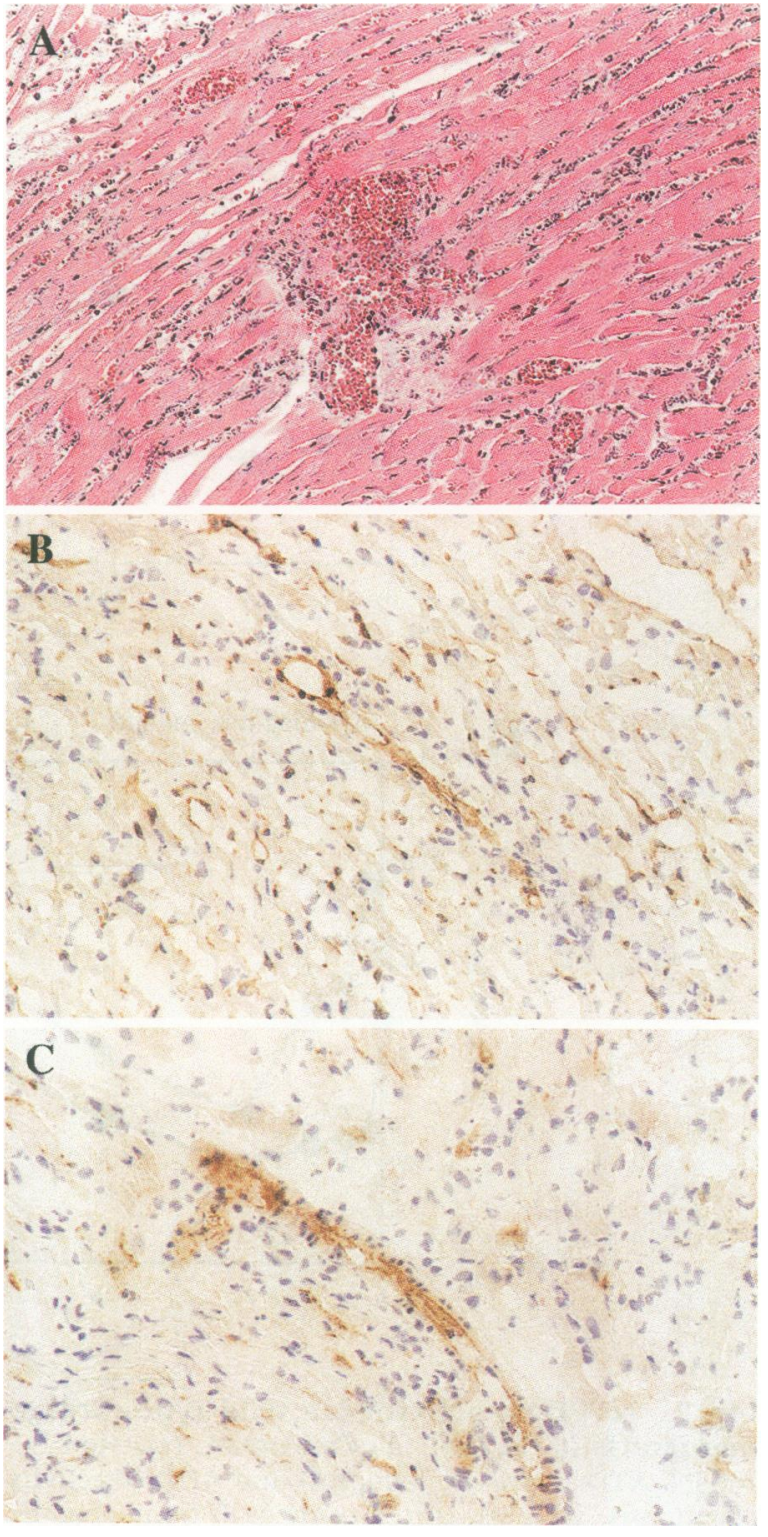

Fig. 4. Immunopathology of concordant xenograft rejection. (A) Hematoxylin and eosin-stained sections; (B) cd39-stained section; (C) P-selectin stain. Representative fields selected from three rejected wild-type xenografts. Vascular thrombosis is evident with extensive P-selectin reactions associated with platelet sequestration within the vasculature. Immunoreactivity for $\operatorname{cd} 39$ is evident within the vasculature.

transplantation (Fig. 2) in a manner analogous to that observed for ischemia reperfusion injury (29) and exposure to oxidant stress $(8,30-32)$. The novel data reported here suggest that NTPDase-1/cd39 biochemical activity levels are immediately influenced by the reperfusion associated with the transplantation procedure. These 


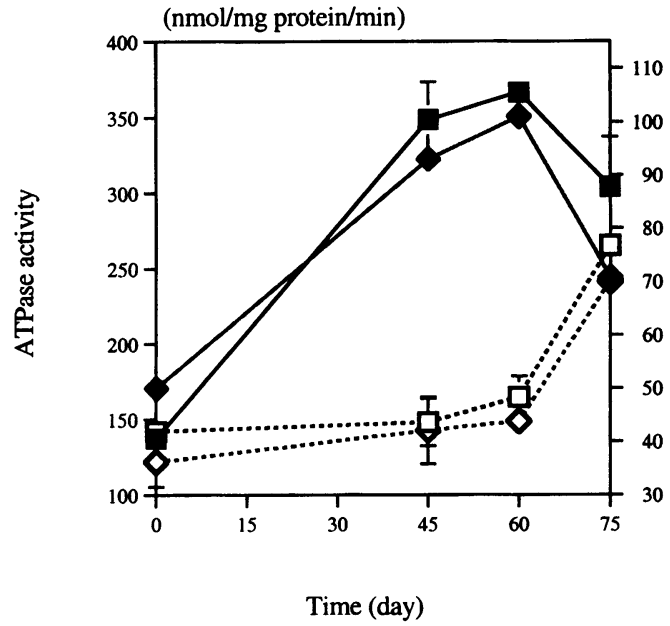

Fig. 5. NTPDase activities in accommodated xenografts. ATPase activity of wild-type grafts $\left(c d 39^{+1+}\right.$, closed squares with solid line) and mutant grafts ( $c d 39^{-1-}$, open squares with dot line), ADPase activity of wild-type grafts (closed diamonds with solid line) and mutant grafts (open diamonds with dot line) were assayed as described in Materials and Methods. Results are the mean \pm SEM for three samples from an accommodated cardiac graft at each time point.

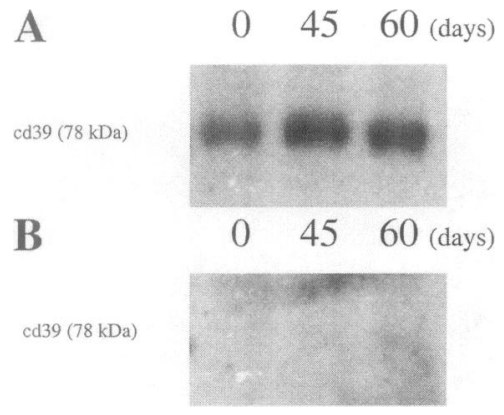

Fig. 6. Western analysis of cd39 expression in accommodated xenografts. (A) Western blotting of $c d 39^{+1+}$ accommodated grafts. (B) Mutant $\left(\mathrm{cd} 39^{-1-}\right)$ accommodated grafts. Increased levels of expression of $\operatorname{cd} 39$ are observed at 45 and 60 days within wild-type grafts only.

results imply that early recovery of NTPDase-1 activities may be important for long-term vascular integrity. At later points, increased or upregulated NTPDase-1 levels were associated with minimal platelet sequestration within the surviving grafts.

Western blotting (Fig. 3A) and immunostaining (Fig. 4B) confirmed that immunoreactive cd39 is expressed on rejected cardiac xenografts. However, concurrent determinations of cd39 mRNA levels (Fig. 1) and NTPDase activity (Fig. 2A) revealed dramatic decreases in the re-
Table 1. Survival of wild-type $\left(\operatorname{cd} 39^{+/+}\right)$and knockout $\left(\mathrm{cd}_{39^{-1-}}\right)$ mouse cardiac xenografts

\begin{tabular}{lll}
\hline Donor & $\begin{array}{l}\text { Treatment } \\
\text { of recipient }\end{array}$ & \multicolumn{1}{c}{$\begin{array}{c}\text { Graft survival } \\
\text { times }\end{array}$} \\
\hline Wild type & Presensitized & $10,20,20 \mathrm{~min}$ \\
Knockout & Presensitized & $10,15,40 \mathrm{~min}$ \\
Wild type & $\begin{array}{l}\text { Presensitized } \\
+ \text { CVF }\end{array}$ & $36,36,48,48,48 \mathrm{hr}$ \\
& Presensitized & $14,16,24,24,36 \mathrm{hr}$ \\
Knockout & + CVF & 2 days $(n=4)$ \\
Wild type & Nil & 2 days $(n=1)$ \\
Knockout & Nil & 4 days $(n=3)$ \\
Wild type & CVF & 4 days $(n=1)$ \\
Knockout & CVF & $>45$ days $(n=6)$ \\
Wild type & CVF + CsA & $>45$ days $(n=4)$ \\
Knockout & CVF + CsA & \\
\hline
\end{tabular}

Presensitized rat recipients were sensitized 7 days prior to transplantation by intraperitoneal injection of $30 \times 10^{6}$ wild-type mouse splenocytes. Where applicable, CVF was injected intraperitoneally $l$ day before and on the day after transplantation. CsA was injected daily intramuscularly until the end of each experiment.

jected grafts. We have previously shown in other systems that levels of cd39 immunoreactivity do not directly correlate with the substantial and simultaneous decreases in the specific expression of NTPDase biochemical activity $(31,38,39)$. We suggest that the persistent expression of immunoreactive $\operatorname{cd} 39$ protein does not indicate the full potential for biochemical activity. Thus, active site perturbation of the NTPDase with loss of activity may occur with maintenance of immunoreactive epitopes within the C-terminal regions.

There were no differences between wildtype $\left(c d 39^{+/+}\right)$and knockout $\left(c d 39^{-/-}\right)$xenograft survival times with respect to hyperacute rejection (presensitized), concordant xenograft rejection (unmodified host), and delayed xenograft rejection models (see Table 1). However, mutant cardiac xenografts were observed to undergo a form of delayed rejection with more rapid vascular occlusion than for matched wild-type organs. These events were observed when these grafts were performed in sensitized rats depleted of complement by using CVF (Table 1). Although such results could imply that $c d 39$ expression may directly modulate antibody-dependent cellular cytotoxicity, many other factors are present in this model and further analysis will be done. 

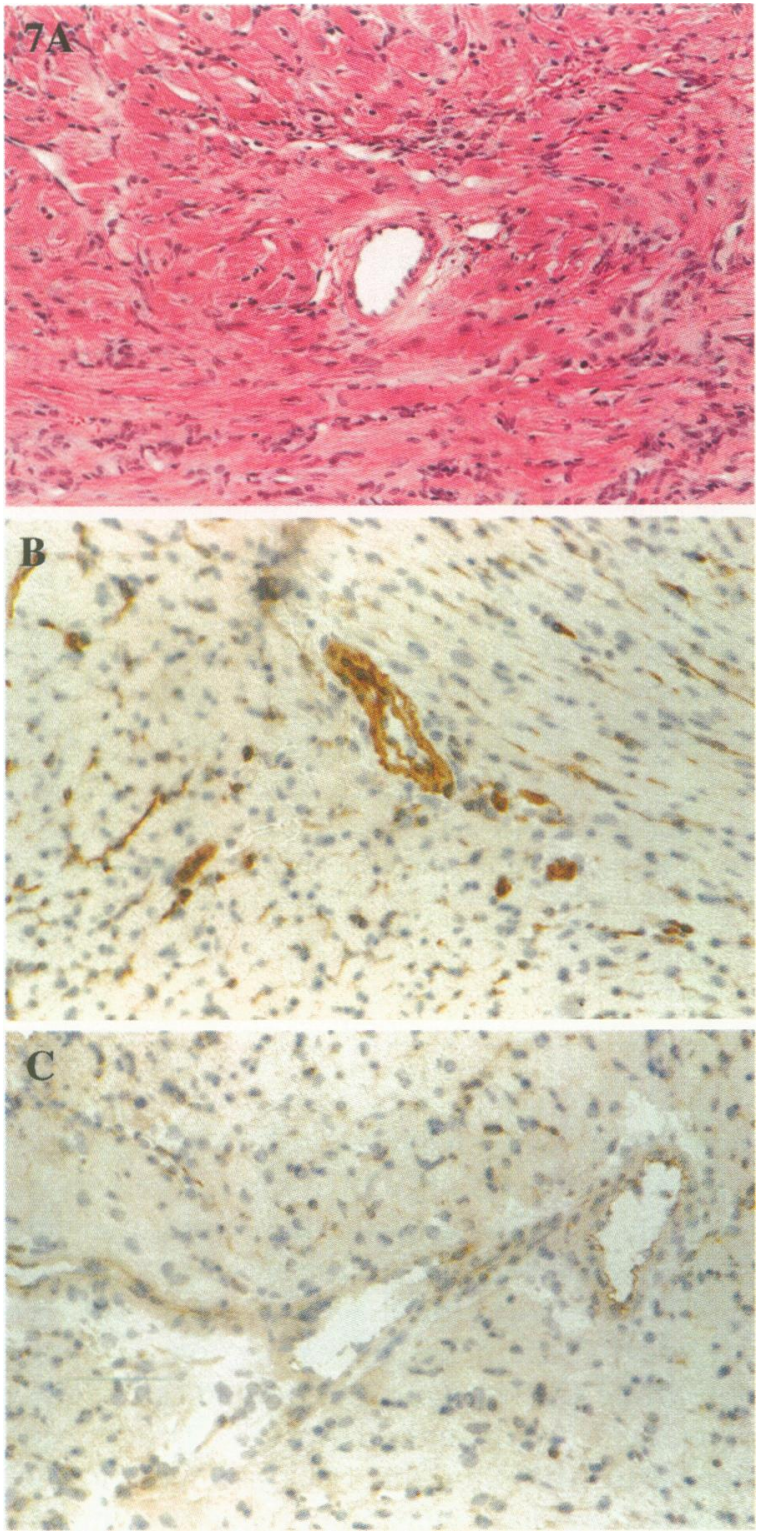

Fig. 7. Immunopathology of wild-type $\left(\mathrm{cd} 39^{+/+}\right)$ accommodated cardiac xenografts. (A) Hematoxylin and eosin-stained section; (B) cd39-stained section; (C) $\mathrm{P}$-selectin stain. Representative fields from accommodated wild-type xenografts. Note the absence of florid vascular lesions and negative P-selectin staining at 60 days after transplantation. High-level staining of cd39 is observed within the vasculature of the grafts. The elements of the rat mononuclear cell infiltrate do not stain for cd39 using the current polyclonal antibodies directed at the mouse protein.

Fig. 8. Immunopathology of mutant $\left(c d 39^{-1-}\right)$ accommodated cardiac xenografts. (A) Hematoxylin and eosin-stained section; (B) cd39-stained section; (C) $\mathrm{P}$-selectin stain. Representative fields from accommodated mutant xenografts at 60 days after transplantation show patchy myocardial injury with deposition of platelets within the vasculature as demonstrated by the Pselectin staining. No reaction for vascular cd39 is noted, as anticipated.
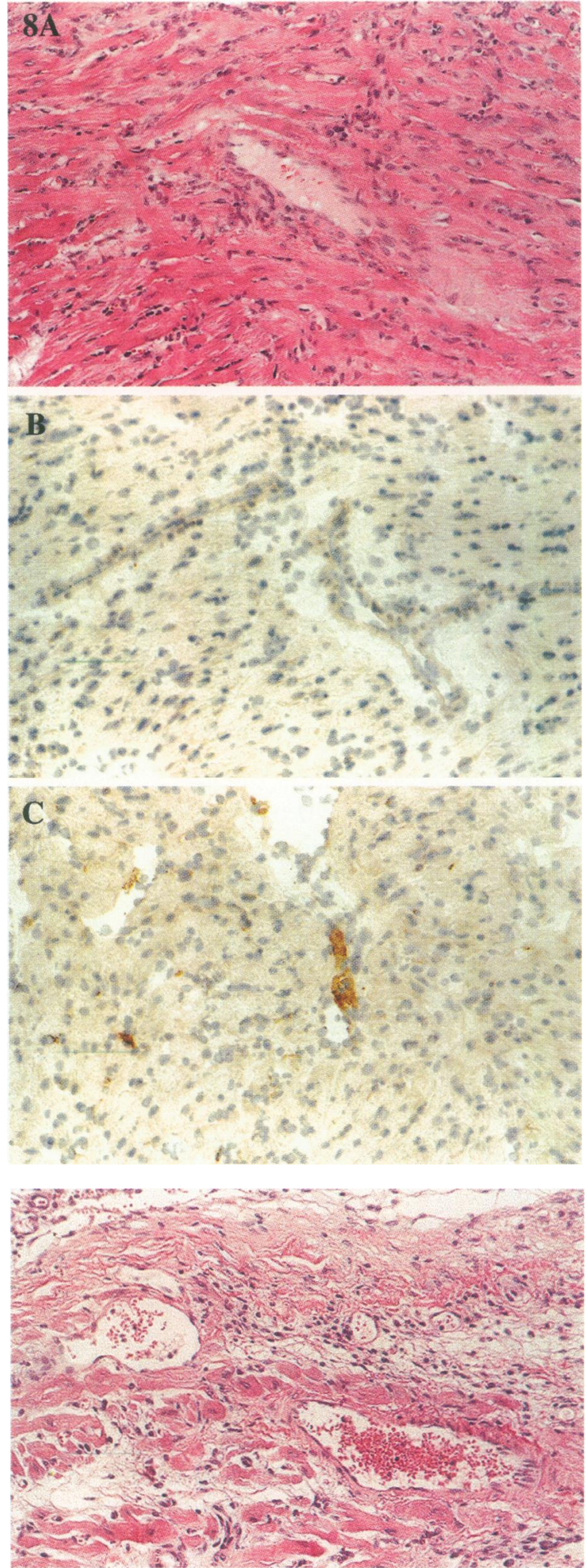

Fig. 9. Histopathology of knockout (cd39-1- $)$ accommodated cardiac xenografts. This hematoxylin and eosin-stained section, a representative field from an accommodated mutant xenograft at 75 days after transplantation, reveals a healing myocardial infarction with fibrosis. 
NTPDase activities of naive nongrafted hearts of both groups of mice were almost at the same levels (Fig. 5). These data may suggest that total ectonucleotidase activities are compensated by NTPDases other than but related to $c d 39$, for example, $c d 3914$ and $c d 3911$. However, NTPDase activities of wild-type grafts increased over 3-fold in accommodated grafts when compared to baseline. Biochemical activities did not increase to 60 days after transplantation in the mutant grafts despite mononuclear cellular infiltration (Figs. 5, 8 ). This observation further suggests either that other cell-associated NTPDases do not become induced within these grafts or they are solubilized and lost.

All surviving grafts from the $c d 39$ null mice $(n=4)$ had P-selectin staining at 45 days posttransplantation. Wild-type accommodated grafts $(n=6)$ did not express P-selectin even up to 75 days after transplantation (data not shown). Infarction was observed only in mutant grafts (Fig. 9). These observations suggest that the process of accommodation requires NTPDase activity to maintain vascular integrity of the graft and mitigate against platelet sequestration. However, other NTPDases expressed in the mutant cardiac grafts appear to compensate, at least in part, for the loss of $c d 39$ and thereby facilitate this extent of survival.

Previous studies indicated that potato apyrase administration (40) and CD39 adenovirus-mediated gene transfer into endothelial cells (41) prolong discordant xenograft survival. Our results also suggest that the intrinsic overexpression of NTPDase activity in surviving xenografts has beneficial effects with respect to the potential for vascular injury and platelet activation. We conclude that NTPDase-1 may play a role in the maintenance of vascular integrity and control of thrombosis in xenografts.

\section{Acknowledgments}

Masato Imai and Ko Takigami contributed equally to this work. This study was supported in part by grants from National Institutes of Health HL 57307 (S.C.R.), POl-41484 (R.D.R.) and American Heart Association GIA 9650490N. The authors are grateful to Elizbieta Kaczmarek and Christian Goepfert for expert assistance, as well as to members of our laboratory for discussion.

\section{References}

1. Bach FH, Robson SC, Ferran C, et al. (1994) Endothelial cell activation and thromboregulation during xenograft rejection. Immunol. Rev. 141: 5-30.

2. Robson SC, Candinas D, Hancock WW, Wrighton C, Winkler H, Bach FH. (1995) Role of endothelial cells in transplantation. Int. Arch. Allergy Immunol. 106: 305-322.

3. Bach FH, Winkler H, Ferran C, Hancock WW, Robson SC. (1996) Delayed xenograft rejection. Immunol. Today 17: 379-384.

4. Bach FH. (1998) Xenotransplantation: problems and prospects. Annu. Rev. Med. 49: 301-310.

5. Robson SC, Young VK, Cook NS, et al. (1996) Thrombin inhibition in an ex vivo model of porcine heart xenograft hyperacute rejection. Transplantation 61: 862-868.

6. Candinas D, Lesnikoski BA, Hancock WW, et al. (1996) Inhibition of platelet integrin GPIIbIIIa prolongs survival of discordant cardiac xenografts. Transplantation 62: 1-5.

7. Robson SC, Schulte am Esch II J, Bach FH. (1999) Factors in xenograft rejection. Ann. N.Y. Acad. Sci. 875: 261-276.

8. Kaczmarek E, Koziak K, Sevigny J, et al. (1996) Identification and characterization of $\mathrm{CD} 39 /$ vascular ATP diphosphohydrolase. J. Biol. Chem. 271: 33116-33122.

9. Cote YP, Picher M, St-Jean P, Beliveau R, Potier $M$, Beaudoin AR. (1991) Identification and localization of ATP-diphosphohydrolase (apyrase) in bovine aorta: relevance to vascular tone and platelet aggregation. Biochim. Biophys. Acta 1078: 187191.

10. Luthje J. (1989) Origin, metabolism and function of extracellular adenine nucleotides in the blood. J. Klin. Wochenschr. 67: 317-327.

11. Plesner L. (1995) Ecto-ATPases: identities and functions. Int. Rev. Cytol. 158: 141-214.

12. Zimmermann H. (1992) 5'-Nucleotidase: molecular structure and functional aspects. Biochem. J. 285: 345-365.

13. Maliszewski CR, Delespesse GJ, Schoenborn MA, et al. (1994) The CD39 lymphoid cell activation antigen. Molecular cloning and structural characterization. J. Immunol. 153: 3574-3583.

14. Wang TF, Guidotti G. (1996) CD39 is an ecto$\left(\mathrm{Ca}^{2+}, \mathrm{Mg}^{2+}\right)$-apyrase. J. Biol. Chem. 271: 98989901.

15. Marcus AJ, Safier LB, Hajjar KA, et al. (1991) Inhibition of platelet function by an aspirin-insensitive endothelial cell ADPase. Thromboregulation by endothelial cells. J. Clin. Invest. 88: 1690-1696.

16. Marcus AJ, Broekman MJ, Drosopoulos JH, et al. (1997) The endothelial cell ecto-ADPase responsible for inhibition of platelet function is CD39. J. Clin Invest. 99: 1351-1360.

17. Dubyak GR, el-Moatassim C. (1993) Signal trans- 
duction via P2-purinergic receptors for extracellular ATP and other nucleotides. Am. J. Physiol. 265: C577-C606.

18. Enjyoji K, Sévigny J, Lin Y, et al. (1999) Targeted disruption of cd39/ATP diphosphohydrolase results in disordered hemostasis and thromboregulation. Nat. Med. 5: 1010-1017.

19. Pearson JD, Gordon JL. (1979) Vascular endothelial and smooth muscle cells in culture selectively release adenine nucleotides. Nature 281: 384-386.

20. Motte S, Communi D, Pirotton S, Boeynaems JM. (1995) Involvement of multiple receptors in the actions of extracellular ATP: the example of vascular endothelial cells. Int. J. Biochem. Cell. Biol. 27: $1-7$.

21. Di Virgilio F. (1995) The P2Z purinoceptor: an intriguing role in immunity, inflammation and cell death. Immunol. Today 16: 524-528.

22. Ferrari D, Chiozzi P, Falzoni S, et al. (1997) Extracellular ATP triggers IL-1 beta release by activating the purinergic $\mathrm{P} 2 \mathrm{Z}$ receptor of human macrophages. J. Immunol. 159: 1451-1458.

23. Marcus AJ, Safier LB. (1993) Thromboregulation: multicellular modulation of platelet reactivity in hemostasis and thrombosis. FASEB J. 7: 516-522.

24. Chinellato A, Froldi G, Caparrotta L, Ragazzi E. (1998) Pharmacological characterization of endothelial cell nitric oxide synthase inhibitors in isolated rabbit aorta. Life Sci. 62: 479-490.

25. Simonsen U, Garcia-Sacristan A, Prieto D. (1997) Involvement of ATP in the non-adrenergic noncholinergic inhibitory neurotransmission of lamb isolated coronary small arteries. Br. J. Pharmacol. 120: $411-420$.

26. Rongen GA, Floras JS, Lenders JW, Thien T, Smits P. (1997) Cardiovascular pharmacology of purines [editorial]. Clin. Sci. (Colch.) 92: 13-24.

27. Bach FH, Robson SC, Winkler H, et al. (1995) Barriers to xenotransplantation [see comments]. Nat. Med. 1: 869-873.

28. Blakely ML, Van der Werf WJ, Berndt MC, Dalmasso AP, Bach FH, Hancock WW. (1994) Activation of intragraft endothelial and mononuclear cells during discordant xenograft rejection. Transplantation 58: 1059-1066.

29. Candinas D, Koyamada N, Miyatake T, et al. (1996) Loss of rat glomerular ATP diphosphohydrolase activity during reperfusion injury is associated with oxidative stress reactions. Thromb. Haemost. 76: 807-812.

30. Robson SC, Daoud S, Begin M, et al. (1997) Mod- ulation of vascular ATP diphosphohydrolase by fatty acids. Blood Coagul. Fibrinolysis 8: 21-27.

31. Robson SC, Kaczmarek E, Siegel JB, et al. (1997) Loss of ATP diphosphohydrolase activity with endothelial cell activation. J. Exp. Med. 185: 153-163.

32. Robson SC, Siegel J, Candinas D, Kopp C, Bach FH. (1996) Loss of ATP diphosphohydrolase activity following endothelial cell activation. Transplant. Proc. 28: 536.

33. Bach FH, Ferran C, Hechenleitner P, et al. (1997) Accommodation of vascularized xenografts: expression of "protective genes" by donor endothelial cells in a host Th2 cytokine environment. Nat. Med. 3: 196-204.

34. Koyamada N, Miyatake $\mathrm{T}$, Candinas $\mathrm{D}$, et al. (1998) Transient complement inhibition plus Tcell immunosuppression induces long-term survival of mouse-to-rat cardiac xenografts. Transplantation 65: 1210-1215.

35. Sevigny J, Levesque FP, Grondin G, Beaudoin AR. (1997) Purification of the blood vessel ATP diphosphohydrolase, identification and localisation by immunological techniques. Biochim. Biophys. Acta 1334: 73-88.

36. Bradford MM. (1976) A rapid and sensitive method for the quantitation of microgram quantities of protein utilizing the principle of proteindye binding. Anal. Biochem. 72: 248-254.

37. Baykov AA, Evtushenko OA, Avaeva SM. (1988) A malachite green procedure for orthophosphate determination and its use in alkaline phosphatasebased enzyme immunoassay. Anal. Biochem. 171: 266-270.

38. Imai M, Kaczmarek E, Koziak K, et al. (1999) Suppression of ATP diphosphohydrolase/CD39 in human vascular endothelial cells. Biochemistry 38: 13473-13479.

39. Schulte am Esch II J, Sévigny J, Kaczmarek E, et al. (1999) Structural elements and limited proteolysis of CD39 influence ATP diphosphohydrolase activity. Biochemistry 38: 2248-2258.

40. Koyamada N, Miyatake T, Candinas D, et al. (1996) Apyrase administration prolongs discordant xenograft survival. Transplantation 62: 17391743.

41. Imai M, Takigami K, Kaczmarek E, et al. (1999) CD39 gene transfer prolongs discordant xenograft survival. In: Abstracts: 5th Congress of the International Xenotransplantation Association 1999, Nagoya. Japanese Xenotransplantation Society, Nagoya, Japan. 